\title{
The Prevention and Management of Contrast-induced Acute Kidney Injury: A Mini-review of the Literature
}

Asad Ali ${ }^{1}$, Chandur Bhan ${ }^{2}$, Muhammad Bilal Malik ${ }^{3}$, Malik Qistas Ahmad ${ }^{4}$, Shahzad Ahmed. Sami ${ }^{1}$

1. Internal Medicine, CMH Lahore Medical College and Institute of Dentistry, Lahore, PAK 2. Internal Medicine, Chandka Medical College Hospital, Larkana, PAK 3. Internal Medicine, Shifa College of Medicine, Lahore, PAK 4. Attock Medical Center, Attock City, Punjab, PAK

$\square$ Corresponding author: Malik Qistas Ahmad, kistasmalic@yahoo.com Disclosures can be found in Additional Information at the end of the article

\section{Abstract}

Contrast-induced acute kidney injury, also called contrast-induced nephropathy, is one of the main causes of acute renal failure/acute kidney injury (AKI) in hospitalized patients within 48 to 72 hours of contrast media administration during various radiologic procedures. Several factors can be responsible for contrast-induced acute tubular necrosis (ATN); however, patient and procedure-related factors play the lead role in determining the development of contrastinduced nephropathy. There is no definitive treatment and hydration remains the mainstay preventive strategy. This article will review the incidence, criteria for definitive diagnosis, and an effective approach on how to prevent contrast-induced nephropathy in a clinical setup.

Categories: Internal Medicine, Preventive Medicine, Nephrology

Keywords: nephropathy, acute tubular necrosis, pharmacologic treatment, nephrotoxicity, contrast induced nephropathy, hemodialysis, radiological, volume expansion, acute kidney injury, nephroprotective

\section{Introduction And Background}

Contrast-induced acute kidney injury, also called contrast-induced nephropathy, is an abrupt deterioration in renal function following administration of iodinated contrast media [1]. Contrast-induced nephropathy (CIN) is most commonly defined as either an absolute $(\geqslant 0.5$ $\mathrm{mg} / \mathrm{dL} ; \geqslant 44 \mu \mathrm{mol} / \mathrm{L}$ ) or relative ( $\geqslant 25 \%$ ) increase in serum creatinine levels at $48-72$ hours after exposure to iodinated contrast media (CM) [2]. It represents the third cause of acute renal failure in hospitalized patients with an estimated incidence of about $12 \%$ [3]. CIN is speculated due to renal damage from acute tubular dysfunction [4] and once the contrast-induced nephropathy is established, there is no definitive treatment, so efforts should be directed toward prevention approaches in order to avoid the event, especially in those with a high risk. There are several studies that analyze the role of multiple prophylactic strategies that have been used to prevent contrast-induced nephropathy and they include volume expansion with sodium chloride or bicarbonate or both, administration of $\mathrm{N}$-acetyl cysteine, statins, hemofiltration or hemodialysis, and reducing the volume of contrast media administered. Despite these varied strategies, there is no clear consensus in clinical practice about the most effective intervention to prevent or reduce this condition. Therefore, further knowledge about the possibility of the presence of this entity by the treating doctor, as a member of a multidisciplinary team including the radiologist, is imperative to distinguish the high-risk factors in patients for developing acute kidney injury (AKI) following parenteral administration 
of radiocontrast agents.

\section{Review}

The use of contrast media in the diagnostic and therapeutic medical arsenal, like interventional cardiology procedures and computed tomography (CT) scans [5], can cause adverse effects such as renal toxicity and acute kidney injury, known as contrast-induced nephropathy (CIN). The estimated incidence is about $7 \%$ to $11 \%$. It is established in the literature that CIN is one of the most important etiological factors of acute kidney injury in hospital settings, and thereby it leads to high health care costs, longer hospital stay, and increased morbidity and mortality [6]. The most recognized definition is an absolute $(\geqslant 0.5 \mathrm{mg} / \mathrm{dl}, \geqslant 44 \mu \mathrm{mol} / \mathrm{l})$ or relative increase $(\geqslant 25 \%)$ in baseline serum creatinine (SCr) value at 48 to 72 hours post-exposure to the contrast media, in the absence of an alternative cause. However, there are many definitions proposed in the world literature. It should be noted that according to the Kidney Disease Improving Global Outcomes guidelines (KDIGO), the recently proposed definition is an increase of $\geqslant 50 \%$ of SCr or $\geqslant 0.3 \mathrm{mg} / \mathrm{dl}$ that usually occurs at 48 hours [7, 8]. In general, the peak of elevation of SCr levels is three to five days post-exposure, returning to normal levels after seven to ten days or even, according to other reports, up to 10-21 days. So contrast-induced nephropathy is considered self-limited and reversible; rarely it causes a persistent renal failure that deserves dialysis [9]. CIN causes kidney damage by acute tubular dysfunction. Many mechanisms are involved in this, namely, renal vasoconstriction [10], toxic effects by the contrast, and oxygen free-radical injury [11]. Once CIN is established, there is no definitive treatment [12], so the most effective strategy remains prevention, especially in those with a high risk of CIN [13].

Promoting factors for the development of nephropathy have been widely described in the literature as well as hydration and pharmacological measures to prevent its development. In this order, with respect to the management, European Renal Best Practice (ERBP) [14] recommends pre-procedure assessment of creatinine concentrations and thus identifying highrisk patients - mostly patients with chronic kidney disease, diabetes mellitus, older age, use of intra-aortic balloon pumps [15], cardiovascular diseases, and people with high C-reactive protein (CRP) levels [16] - to whom a repeat serum creatinine test 12 and 72 hours after administration of the contrast media should be performed. A simple risk score for CIN has been developed for patients undergoing percutaneous coronary intervention (PCI) [17]. This enables the clinician to be prepared for an event if it occurs. On the other hand, it is recommended that clinicians evaluate the benefit: risk ratio of interventions with contrast administration mainly in high-risk patients, consider alternative imaging methods without contrast, with diagnostic accuracy similar to the first. As risk factors of CIN, the volume of contrast applied and the use of concurrent nephrotoxic medication (nonsteroidal anti-inflammatory drugs, aminoglycosides, amphotericin B, high doses of loop diuretics, and antiviral drugs like acyclovir and foscarnet) can be mentioned [18-23]. Therefore, minimizing the volume of CM used and avoiding the use of nephrotoxic medications whenever possible are mandatory prevention measures [24].

Furthermore, an adequate fluid and electrolyte support is one of the most effective prevention strategies for CIN [25]. So, ERBP suggests volume expansion with either isotonic sodium chloride or sodium bicarbonate solutions [26]. Also, the oral route for hydration is possible, as long as an adequate intake of fluid and salt are assured. The mechanism by which it reduces risk is not well understood; however, what is postulated is that the dilution of contrast media may subsequently decrease the nephrotoxicity. Hydration also causes the inhibition of reninangiotensin-aldosterone system (RAAS) [27], minimizing renal vasoconstriction and hypoxia. When normal saline is used, an intravenous regime of $1.0-1.5 \mathrm{ml} / \mathrm{kg} / \mathrm{h}$ for at least six hours before and after contrast medium administration is recommended. For sodium bicarbonate $[28,29]$, the most widely used regimen $(3 \mathrm{ml} / \mathrm{kg} / \mathrm{h}$ for one hour before contrast medium followed by $1 \mathrm{ml} / \mathrm{kg} / \mathrm{h}$ for six hours after) seems appropriate [30, 31]. 
In addition to pharmacological prevention strategies, $\mathrm{N}$-acetyl cysteine [32] can be used as a preventive therapy. Its nephroprotective role is attributed to its antioxidant and vasodilatory properties, which increase nitric oxide vasodilator activity [33]); however, this should be used in conjunction with proper volume expansion. Others like theophylline, fenoldopam, and ascorbic acid failed to show any protective effect against CIN [34-37]. Statins have a beneficial role $[38,39]$ in CIN wherein they improve endothelial dysfunction and decrease oxidative stress, although, there are not enough trials to prove this benefit as conclusive [40-42].

In the same way, hemofiltration has been proven effective in the prevention of CIN [43, 44]; however, future studies are necessary prior to its establishment as a systematic prophylactic measure [45] in patients with kidney injury. Hemodialysis, however, is not recommended [46]. Newer agents like the non-ionic low and iso-osmolar contrast media been developed, which have promised to reduce the incidence of CIN in patients [47].

Contrast-induced nephropathy is a condition in which deterioration of renal function occurs due to exposure to iodinated contrast medium and one that doesn't have an effective therapy available to treat it. So the best option for the management of CIN is prevention. Despite the existing varied strategies-maintain adequate volume expansion in the peri-procedure period, minimize the volume of contrast media, avoid the use of nephrotoxic medications whenever possible-no clear consensus exists in clinical practice about the most effective intervention to prevent or reduce CIN. Some promising trials are in process that suggest a transradial approach instead of transfemoral access for prevention of CIN, and more evidence on this is yet to be elucidated [48].

\section{Conclusions}

The knowledge of contrast-induced nephropathy is one of the most important points for its prevention, considering that the treating physician is the main link in this chain together with the radiologist and the patient. Consequently, it is expected to minimize the inappropriate use of the contrast media administered in radiological studies.

\section{Additional Information \\ Disclosures}

Conflicts of interest: In compliance with the ICMJE uniform disclosure form, all authors declare the following: Payment/services info: All authors have declared that no financial support was received from any organization for the submitted work. Financial relationships: All authors have declared that they have no financial relationships at present or within the previous three years with any organizations that might have an interest in the submitted work. Other relationships: All authors have declared that there are no other relationships or activities that could appear to have influenced the submitted work.

\section{References}

1. Singh J, Daftary A: Iodinated contrast media and their adverse reactions. J Nucl Med Technol. 2008, 36:69-74. 10.2967/jnmt.107.047621

2. Azzalini L, Spagnoli V, Ly HQ: Contrast-induced nephropathy: from pathophysiology to preventive strategies. Can J Cardiol. 2016, 32:247-55. 10.1016/j.cjca.2015.05.013

3. Mohammed NMA, Mahfouz A, Achkar K, Rafie IM, Hajar R: Contrast-induced nephropathy. Heart Views. 2013, 14:106-116. 10.4103/1995-705X.125926

4. Tepel M, Aspelin P, Lameire N: Contrast-induced nephropathy: a clinical and evidence-based approach. Circulation. 2006, 113:1799-806.

5. Loh S, Bagheri S, Katzberg RW, Fung MA, Li CS: Delayed adverse reaction to contrastenhanced CT: a prospective single-center study comparison to control group without 
enhancement. Radiology. 2010, 255:764-71. 10.1148/radiol.10091848

6. Jorgensen AL: Contrast-induced nephropathy: pathophysiology and preventive strategies. Crit Care Nurse. 2013, 33:37-46. 10.4037/ccn2013680

7. Subramaniam RM, Suarez-Cuervo C, Wilson RF, et al.: Effectiveness of prevention strategies for contrast-induced nephropathy: a systematic review and meta-analysis. Ann Intern Med. 2016, 164:406-416. 10.7326/M15-1456

8. The ad-hoc working group of ERBP, Fliser D, Laville M, et al.: A European Renal Best Practice (ERBP) position statement on the Kidney Disease Improving Global Outcomes (KDIGO) clinical practice guidelines on acute kidney injury: part 1: definitions, conservative management and contrast-induced nephropathy. Nephrol Dial Transplant. 2012, 27:42634272. 10.1093/ndt/gfs375

9. Maioli M, Toso A, Leoncini M, Gallopin M, Musilli N, Bellandi F: Persistent renal damage after contrast-induced acute kidney injury: incidence, evolution, risk factors, and prognosis. Circulation. 2012, 125:3099-107.

10. Wong PC, Li Z, Guo J, Zhang A: Pathophysiology of contrast-induced nephropathy. Int J Cardiol. 2012, 158:186-92. 10.1016/j.ijcard.2011.06.115

11. Katholi RE, Woods WT Jr, Taylor GJ, Deitrick CL, Womack KA, Katholi CR, McCann WP: Oxygen free radicals and contrast nephropathy. Am J Kidney Dis. 1998, 32:64-71. 10.1053/ajkd.1998.v32.pm9669426

12. Ellis JH, Cohan RH: Reducing the risk of contrast-induced nephropathy: a perspective on the controversies. Am J Roentgenol. 2009, 192:1544-1549. 10.2214/AJR.09.2368

13. Faggioni M, Mehran R: Preventing contrast-induced renal failure: a guide . Interv Cardiol. 2016, 11:98-104. 10.15420/icr.2016:10:2

14. Farrington K, Covic A, Aucella F, et al.: Clinical practice guideline on management of older patients with chronic kidney disease stage $3 b$ or higher (eGFR $<45 \mathrm{~mL} / \mathrm{min} / 1.73 \mathrm{~m} 2$ ). Nephrol Dial Transplant. 2016, 31:1-66. 10.1093/ndt/gfw356

15. Mehran R, Aymong ED, Nikolsky E, et al.: A simple risk score for prediction of contrastinduced nephropathy after percutaneous coronary intervention: development and initial validation. J Am Coll Cardiol. 2004, 44:1393-9. 10.1016/j.jacc.2004.06.068

16. Evola S, Lunetta M, Macaione F, et al.: Risk factors for contrast induced nephropathy: a study among Italian patients. Indian Heart J. 2012, 64:484-491. 10.1016/j.ihj.2012.07.007

17. Sgura FA, Bertelli L, Monopoli D, et al.: Mehran contrast-induced nephropathy risk score predicts short- and long-term clinical outcomes in patients with ST-elevation-myocardial infarction. Circ Cardiovasc Interv. 2010, 3:491-8.

18. Dixit M, Doan T, Kirschner R, Dixit N: Significant acute kidney injury due to non-steroidal anti-inflammatory drugs: inpatient setting. Pharmaceuticals (Basel). 2010, 3:1279-1285. 10.3390/ph3041279

19. Fanos V, Cataldi L: Amphotericin B-induced nephrotoxicity: a review. J Chemother. 2000, 12:463-70. 10.1179/joc.2000.12.6.463

20. Mingeot-Leclercq M-P, Tulkens PM: Aminoglycosides: nephrotoxicity. Antimicrobial agents and chemotherapy. Antimicrob Agents Chemother. 1999, 43:1003-1012.

21. Karajala V, Mansour W, Kellum JA: Diuretics in acute kidney injury. Minerva Anestesiol. 2009, $75: 251-7$.

22. Yildiz C, Ozsurekci Y, Gucer S, Cengiz AB, Topaloglu R: Acute kidney injury due to acyclovir . CEN Case Rep. 2013, 2:38-40. 10.1007/s13730-012-0035-0

23. Deray G, Martinez F, Katlama C, et al.: Foscarnet nephrotoxicity: mechanism, incidence and prevention. Am J Nephrol. 1989, 9:316-321. 10.1159/000167987

24. Gupta RK, Bang TJ: Prevention of contrast-induced nephropathy (CIN) in interventional radiology practice. Seminars in interventional radiology. Semin Intervent Radiol. 2010, 27 : 348-359. 10.1055/s-0030-1267860

25. Solomon R: Improving intravenous fluid therapy for prevention of contrast-induced nephropathy. How to give more without causing heart failure. JACC Cardiovasc Interv. 2016, 9:97-9.10.1016/j.jcin.2015.10.014

26. Andreucci M, Solomon R, Tasanarong A: Side effects of radiographic contrast media: pathogenesis, risk factors, and prevention. Biomed Res Int. 2014, 2014:741018. $10.1155 / 2014 / 741018$

27. Ba Aqeel SH, Sanchez A, Batlle D: Angiotensinogen as a biomarker of acute kidney injury . Clin Kidney J. 2017, 10:759-768. 10.1093/ckj/sfx087 
28. Lefel N, Janssen L, le Noble J, Foudraine N: Sodium bicarbonate prophylactic therapy in the prevention of contrast-induced nephropathy in patients admitted to the intensive care unit of a teaching hospital: a retrospective cohort study. J Intensive Care. 2016, 4:5. 10.1186/s40560-016-0127-6

29. Tamai N, Ito S, Nakasuka K, et al.: Sodium bicarbonate for the prevention of contrast-induced nephropathy: the efficacy of high concentration solution. J Invasive Cardiol. 2012, 24:439-42.

30. Shemirani H, Pourrmoghaddas M: A randomized trial of saline hydration to prevent contrastinduced nephropathy in patients on regular captopril or furosemide therapy undergoing percutaneous coronary intervention. Saudi J Kidney Dis Transpl. 2012, 23:280-5.

31. Mahmoodi K, Sohrabi B, Ilkhchooyi F, Malaki M, Khaniani ME, Hemmati M: The efficacy of hydration with normal saline versus hydration with sodium bicarbonate in the prevention of contrast-induced nephropathy. Heart Views. 2014, 15:33-36. 10.4103/1995-705X.137489

32. Jo S-H: N-acetylcysteine for prevention of contrast-induced nephropathy: a narrative review . Korean Circ J. 2011, 41:695-702. 10.4070/kcj.2011.41.12.695

33. Myers SI, Wang L, Liu F, Bartula LL: Iodinated contrast induced renal vasoconstriction is due in part to the downregulation of renal cortical and medullary nitric oxide synthesis. J Vasc Surg. 2006, 44:383-91. 10.1016/j.jvs.2006.04.036

34. Bagshaw SM, Ghali WA: Theophylline for prevention of contrast-induced nephropathy: a systematic review and meta-analysis. Arch Intern Med. 2005, 165:1087-93.

10.1001/archinte.165.10.1087

35. Bilasy ME, Oraby MA, Ismail HM, Maklady FA: Effectiveness of theophylline in preventing contrast-induced nephropathy after coronary angiographic procedures. J Interv Cardiol. 2012, 25:404-10. 10.1111/j.1540-8183.2012.00730.x

36. Caixeta A, Dogan O, Weisz G: Contrast-induced nephropathy: protective role of fenoldopam . Clin Exp Pharmacol Physiol. 2012, 39:497-505. 10.1111/j.1440-1681.2012.05707.x

37. Dvoršak B, Kanič V, Ekart R, Bevc S, Hojs R: Ascorbic acid for the prevention of contrastinduced nephropathy after coronary angiography in patients with chronic renal impairment: a randomized controlled trial. Ther Apher Dial. 2013, 17:384-90. 10.1111/1744-9987.12083

38. Toso A, Maioli M, Leoncini M, et al.: Usefulness of atorvastatin ( $80 \mathrm{mg}$ ) in prevention of contrast-induced nephropathy in patients with chronic renal disease. Am J Cardiol. 2010, 105:288-92. 10.1016/j.amjcard.2009.09.026

39. Xinwei J, Xianghua F, Jing Z, et al.: Comparison of usefulness of simvastatin $20 \mathrm{mg}$ versus 80 $\mathrm{mg}$ in preventing contrast-induced nephropathy in patients with acute coronary syndrome undergoing percutaneous coronary intervention. Am J Cardiol. 2009, 104:519-24. 10.1016/j.amjcard.2009.04.014

40. Singh N, Lee JZ, Huang JJ, et al.: Benefit of statin pretreatment in prevention of contrastinduced nephropathy in different adult patient population: systematic review and metaanalysis. Open Heart. 2014, 1 :e000127. 10.1136/openhrt-2014-000127

41. Barbieri L, Verdoia M, Schaffer A, Nardin M, Marino P, De Luca G: The role of statins in the prevention of contrast induced nephropathy: a meta-analysis of 8 randomized trials. J Thromb Thrombolysis. 2014, 38:493-502. 10.1007/s11239-014-1076-3

42. Zhang T, Shen LH, Hu LH, He B: Statins for the prevention of contrast-induced nephropathy: a systematic review and meta-analysis. Am J Nephrol. 2011, 33:344-51. 10.1159/000326269

43. Choi MJ, Yoon JW, Han SJ, et al.: The prevention of contrast-induced nephropathy by simultaneous hemofiltration during coronary angiographic procedures: a comparison with periprocedural hemofiltration. Int J Cardiol. 2014, 176:941-5. 10.1016/j.ijcard.2014.08.095

44. Ghani AA, Hussain N, Al Helal B: Can continuous venovenous hemofiltration prevent contrast-agent induced nephropathy in patients with advanced chronic kidney disease after coronary angiography?. Saudi J Kidney Dis Transpl. 2011, 22:54-60.

45. Kawashima S, Takano H, Iino Y, Takayama M, Takano T: Prophylactic hemodialysis does not prevent contrast-induced nephropathy after cardiac catheterization in patients with chronic renal insufficiency. Circ J. 2006, 70:553-8. 10.1253/circj.70.553

46. Tepel M: Does prophylactic haemodialysis protect kidney function after angiography? . Nephrol Dial Transplant. 2008, 23:1473-1475. 10.1093/ndt/gfn019

47. Andreucci M, Faga T, Pisani A, Sabbatini M, Russo D, Michael A: The choice of the iodinated radiographic contrast media to prevent contrast-induced nephropathy. Adv Chronic Kidney Dis. 2008, 2014:11. 10.1155/2014/691623

48. Kooiman J, Seth M, Dixon S, Wohns D, LaLonde T, Rao SV, Gurm HS: Risk of acute kidney 
Cureus

injury after percutaneous coronary interventions using radial versus femoral vascular access: insights from the Blue Cross Blue Shield of Michigan Cardiovascular Consortium. Circ Cardiovasc Interv. 2014, 7:190-8. 